Article

\title{
Why Companies Do Not Renew Their EMAS Registration? An Exploratory Research
}

\author{
Michele Preziosi ${ }^{1,+}$, Roberto Merli ${ }^{1, *}$ and Mara D'Amico ${ }^{2,+}$ \\ 1 Department of Business Studies, Roma Tre University, Via Silvio D’Amico 77, 00145 Rome, Italy; \\ michelepreziosi@gmail.com \\ 2 ISPRA - Italian Institute for Environmental Protection and Research, Via Vitaliano Brancati 48, \\ 00144 Rome, Italy; mara.damico@isprambiente.it \\ * Correspondence: roberto.merli@uniroma3.it; Tel.: +39-06-5733-5813 or +39-335-7107033 \\ + These authors contributed equally to this work.
}

Academic Editor: Manfred Max Bergman

Received: 30 December 2015; Accepted: 16 February 2016; Published: date

\begin{abstract}
The Eco-Management and Audit Scheme (EMAS) is the official Environmental Management System (EMS) issued by the European Union (EU). Italy is the country where EMAS is most widespread, accounting for over 1000 registered organizations. Since the entry into the force of the Regulation in 1997, the number of registrations has constantly grown until 2008, when the figures started to drop. The phenomena are due to both the decrease of the annual registration rate and the lack of renewals. According to the Italian Institute for Environmental Protection and Research (ISPRA), in recent years, an increasing number of organizations decided to withdraw from EMAS registration. The purpose of this paper is to analyze the reasons of this negative trend. The first step consisted of a literature review concerning the main barriers, difficulties and costs incurred by EMAS-registered organizations. Subsequently, this information was integrated with data about the evolution of EMAS registrations and the results of a previous survey, which involved the entire population of Italian registered firms. The present exploratory research highlighted economic and operational domains concerning the cancellation trends that deserve a deeper investigation, which will be conducted through a questionnaire addressed to Italian firms that did not renew the registration in the last lustrum. The intended output will allow us to identify stakeholders' priority intervention areas in order to suggest an operative strategy to reduce EMAS cancellation rates, addressed to Member States (MS) Competent Bodies.
\end{abstract}

Keywords: eco-management and audit scheme; EMAS; environmental management systems; EMS; ISO 14001; European Community

\section{Introduction}

Nowadays firms that want to compete in the global market need to fulfill the requests of several stakeholder categories, both internal and external [1-3]. Environmental sustainability is becoming a determinant requirement for institutions and citizens, which allows the firms to succeed $[4,5]$. To meet stakeholders' requirements, firms need to introduce environmentally related measures $[6,7]$. Three main families of instruments are available to manage environmental resources toward sustainability: command and control, market-based, and voluntary instruments [8,9]. The latter category indicates a proactive attitude towards the environment as a critical factor for firms to maintain competitiveness [10]. Since the 1990s, the European community has fostered proactive environmental policy instruments. Among the more flexible instruments, Environmental Managements Systems (EMSs) emerged [11]. The Environmental Management Systems (EMSs) represent a way through which firms can internalize environmental issues [12], showing a proactive 
attitude toward sustainability [13]. Up to today, the main international reference standards for EMSs are ISO 14001 Certification and the European EMAS (Eco Management and Audit Scheme) Regulation [14-16]. In Europe, the Fifth Environmental Action Plan (5EAP) recognized the importance of the introduction of voluntary instruments for firms and, in 1993, the first EMAS regulation was issued (Regulation (EC) No 1836/1993) [17]. In 2009, the third revision was launched (Regulation (EC) No1221/2009), and now a new revision of the scheme is in progress. On the other hand, the ISO 14001 scheme was issued for the first time in 1996 and in 2015 a new version was published (ISO 14001:2015).

Italy is the country where the most organizations are registered according to the EMAS scheme, but since 2012 a significant reduction of registrations has been observed, with a parallel increase of EMAS drop-outs in the country. The goal of the paper is to give an overview of this recent phenomenon, examining figures and characteristics of Italian companies that are registered with EMAS and of those that withdrew from EMAS in the last five years. The output of the analysis is intended to be a support to better understand which categories of organizations are more involved in this process of EMAS registration withdrawals. In the first section the main findings of surveys conducted both on ISO 14001 and EMAS are summarized, focusing on difficulties and barriers that firms deal with, in the implementation of the EMSs. Then, with the help of the ISPRA (Superior Institute for Environmental Protection and Research (http://www.isprambiente.gov.it/) dataset, the trends and main characteristics of firms that withdrew from EMAS since the enactment of its last revision (EMAS III) are reported.

\section{Barriers and Challenges that Organizations Face in the Implementation of the EMSs}

Given that the aim of the article is to better understand why companies drop out from a standardized EMS, in this paragraph, results from studies investigating critical aspects of ISO 14001 and EMAS EMSs are summarized.

One of the main barriers found in the implementation of EMSs relates to the difficulty of attributing positive outcomes directly to the EMS [14]. This finding is confirmed by Hillary (2004), who underlines a lack of awareness of EMS benefits [18].

Scholars also analyzed differences in the impact of the two EMS certifications. Generally, the adoption of the two standards is motivated by different factors. ISO 14001 is mainly motivated by external factors, such as industry associations and client pressures. On the other hand, EMAS is more internally driven, and it can be considered a premium standard [11]. Moreover, according to HerasSaizarbitoria et al. (2015), EMAS is more internally focused. Firms aim to obtain positive outcomes from improved internal processes [19]. Generally, a firm's size influences the internalization of proactive environmental practices. Small firms and micro-firms tend to adopt proactive measures mainly driven by external pressures and may be driven by clients' requirements and competitors' choices [20].

The main goal of EMSs is the improvement of environmental performances. Daddi et al. (2014) investigated the effect of ISO 14001 and EMAS in terms of the reduction of environmental impacts. Both systems have a positive impact in energy-intensive industries. Nevertheless, ISO 14001 is more effective in the short term, while EMAS firms obtain better results in the long run [21].

\subsection{ISO 14001: Firms' Constraints and Difficulties}

ISO 14001 is the most common EMS certification. Worldwide, over 300,000 companies are certified with this standard in over 170 countries [22]. The rate of growth of the certification has constantly increased since its came into being and, together with ISO 9001, it is the main global management standard [23]. Recently, the growth has been faster in developing countries and in the Far East, which started to promote the standard to increase firms' competitiveness and, thus, exports [24].

Concerning different sectors, the standard's diffusion is quite homogeneous worldwide. Moreover, there is no imbalance among activities over time. However, sectors with a higher spread of certification are "basic metal and fabricated metal products", "electrical and optical equipment", the "food industry" and "machinery and transport" [25]. 
Many surveys have been conducted to investigate firms' perceptions of the certification. The results of these studies vary significantly in relation to a company's sector, dimension and national context $[14,26,27]$.

Some studies, described in the next paragraph, focus on specific countries, while others contain an international sample of organizations. Moreover, the aspects investigated may differ between drivers, benefits and critical aspects of ISO 14001 certification. The literature review performed on the certification did not identify any study that focused on the analysis of reasons and motivations behind a firm's decision to drop out of ISO 14001.

The application of the standard is not necessarily followed by net benefits for companies. In some cases a negative outcome was reported due to the non-realization of expected benefits $[18,28]$. One of the main constraints in evaluating the certification concerns the uncertainty of the benefits generated [29]. The EMS brings some long-term and immaterial benefits that seem difficult to estimate, such as company reputation and avoidance of accidents [30-32]. He et al. (2015), analyzing the financial performances of firms adopting ISO 14001, state that it is still unclear whether its adoption determines a net economic value [33]. Moreover, it is quite complicated to calculate the environmental improvements directly linked to the system's implementation [14,34,35]. According to Arena, Azzone and Platti (2012), the standard seems to be particularly ineffective in response to clients' requests, implementation of a green marketing strategy and cost reductions [36]. In addition, companies encounter several difficulties when implementing the EMSs. First, costs of implementation and maintenance are often higher than expected, especially for small and medium enterprises (SMEs)[28,31,37-41]. Another barrier is the complexity of operations and methodologies required to implement the EMS, especially when there is a lack of internal staff expertise [18,30,37,40-44]. Also, the necessary compliance with legislation is a significant barrier to implementation [32]. Other difficulties concern organizational structure and culture as well as low commitment of management [18,28,31,45-47]. Disadvantages of certification also concern a lack of market recognition, difficulties in meeting stakeholders' and consumers' demands, and inefficient external communication activities [18,41]. Some surveys pointed out that companies often remark on the lack of governmental and institutional support $[18,30,42,47,48]$.

Another interesting aspect to consider is the case of the abandonment of Integrated Management Systems (IMS). The main difficulties in implementing IMS are the complexity of organizational systems, organizational problems, overabundant documentation, and the initial cost [49]. Moreover, critical issues are the lack of integration guidelines, lack of expertise, lack of management commitment, and difficulty in assigning the correct level of importance to all management system dimensions [50,51]. Gianni and Gotzamani (2015) investigated the case of an IMS's failure. The authors found out that the main reason for dropping out of the system was the missing and/or unevaluated strategic perception of it, showed by the top management [52].

\subsection{EMAS: Firms' Constraints and Difficulties}

In 2012, Heras-Saizarbitoria et al. (2015) obtained 361 responses from Spanish EMAS organizations through a survey (with a response rate of $26.66 \%$ ). The goal was to analyze the intention of Spanish organizations to renew EMAS registration, analyzing motivations, obstacles and benefits of the regulation. Over $11 \%$ of respondents affirmed that they will not renew the registration, while $45 \%$ expressed doubts on the future renewal. The authors found out that the renewal rate is positively correlated with significant internal reasons to improve organizations' environmental performances. On the other hand, the costs sustained to obtain EMAS are not significant in terms of the decision to maintain it in the future. Moreover, EMAS adoption seems to be mainly driven by public incentives: firms that received incentives have a higher likelihood to not renew it [53].

In the EVER (Evaluation of EMAS and Eco-label for their Revision) study, some organizations that dropped out of EMAS were interviewed. One of the main reasons to not renew the EMS was that there is no perceived added value with respect to ISO 14001 (which is more often required by clients) [54].

Specifically considering the analysis of the reasons for dropping out of EMAS, Ahsen, Von Lange and Pianovski conducted telephone interviews with organizations that did not renewed the scheme 
in Northrhine-Westfalia [55]. The most frequent reason for dropping out of EMAS was that "the public does not care about environmental statements". Secondly, companies are "disappointed about the low degree of regulatory relief" offered to EMAS-registered companies. Lastly, nearly half of the interviewees stressed that they have certified their environmental management systems according to ISO 14001 [55].

In 2009, Vernon et al. used a questionnaire to interview 25 European organizations that withdrew from EMAS. The most important reason to leave the scheme was the unclear or insufficient benefits to justify registration, followed by the preference for other types of EMSs and a lack of internal management culture. Other important elements identified are the lack of incentives from member states and the cost of implementation and registration. The respondents also pointed out that supply customers no longer require EMAS registration [56].

\section{Facts and Figures about EMAS-Registered Organizations}

By the end of 2014, in Europe, 3341 organizations were registered according to the EMAS scheme, accounting for over 10,000 sites. Italy is the leading country for the number of registered organizations and sites (respectively, 1058 and 5938), followed by Spain with 908 organizations and 1045 sites and Germany with 315 organizations and 489 sites. Analyzing the official figures from the European Union and the Italian competent body for EMAS, it is evident that, despite the introduction of the new version of the regulation in 2009, the level of diffusion of the scheme among European organizations was constantly decreasing by mid-2012.

Assuming 2010 as the reference year for the implementation of the last version, from January 2010 to January 2015 the organizations declined from 4434 to 3341, with about a $25 \%$ reduction. In the same period of observation, a less noticeable reduction also occurred in Italy, with a decrease of $5 \%$.

With the aid of the internal database of ISPRA, an in-depth analysis of the Italian trend of registrations has been carried out. Figure 1 shows the delta between new registrations and withdrawals during the period 2002-2015. Considering the last five years (since the implementation of EMAS III), EMAS is reducing its diffusion. For the first time, in 2012, the tradeoff between new registrations and withdrawals was negative. As shown in Figure 1, this negative trend is remarkable for the last period: in 2014 the delta was -26, while in the first quarter of 2015 it was -68 .

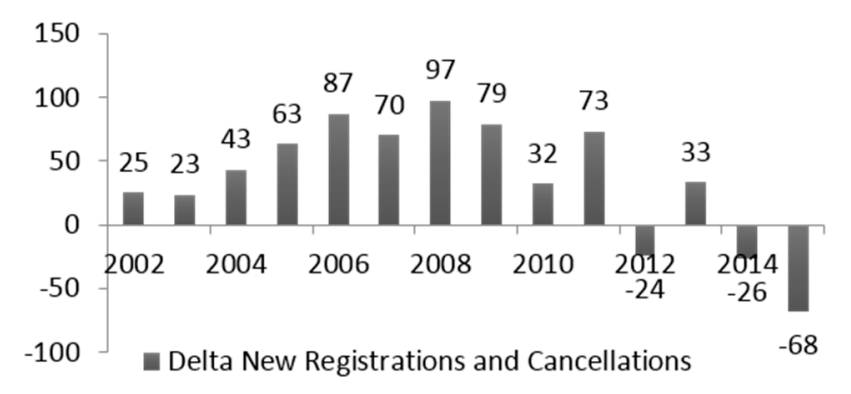

Figure 1. Delta between new EMAS registrations and withdrawals in Italy. Source: authors' elaboration on ISPRA database.

Taking into account that the diffusion of EMAS is part of the European strategy to reduce firms' impact on the environment, and given the speed of this declining process, an analysis of the firms that withdrew from EMAS seems crucial, together with an improved comprehension of which instruments and policies could result in a more efficient increase in the number of registrations.

\section{Characteristics of Organizations That Drop out of EMAS in Italy}

Since 2002, 509 organizations withdrew from EMAS. Notably, the period between 2010 and the first quarter of 2015 has been the most critical, accounting for $76.82 \%$ of the total (Figure 2). Of these 
391 organizations, more than half are small (56.01\%). Considering the geographic distribution, $44.50 \%$ are located in the north, $35.55 \%$ are in southern Italy and $19.95 \%$ are in the central regions (Figure 3).

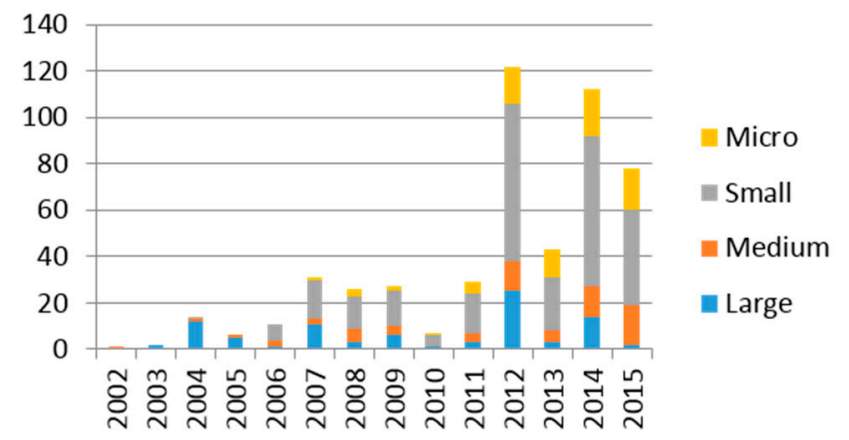

Figure 2. EMAS withdrawals by type of organization in Italy. Source: authors' elaboration on ISPRA database.

\section{EMAS cancellations (A)}

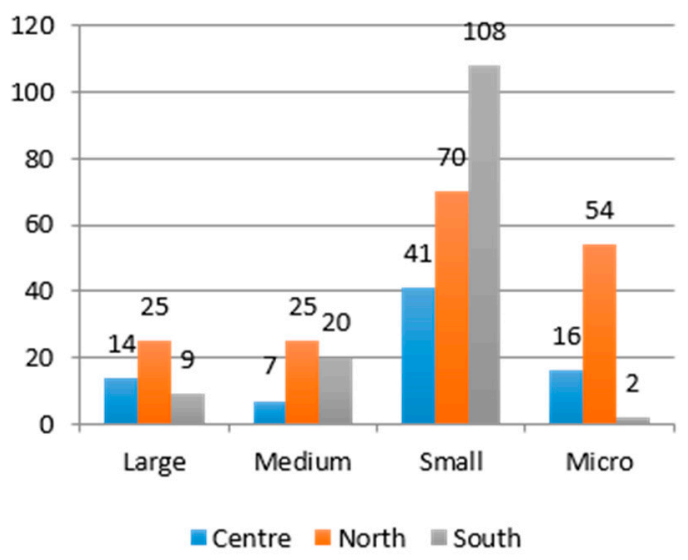

Figure 3. EMAS withdrawals by geographic area and dimension (2010 and first quarter 2015). Source: authors' elaboration on ISPRA database.

In order to better understand the phenomenon, data have been compared with those from the organizations that have an active EMAS registration. Taking into account organizations' dimensions, the active registrations are homogeneously distributed among the four categories. Conversely, the quota of small organizations that withdrew from EMAS in the last five years is remarkable $(56.01 \%)$ (Table 1).

Table 1. EMAS active registrations (first quarter of 2015) and withdrawals (2010 to first quarter of 2015) per organization dimension.

\begin{tabular}{ccccc}
\hline & \multicolumn{2}{c}{$\begin{array}{c}\text { Active registrations } \\
\text { First Quarter }\end{array}$} & \multicolumn{2}{c}{$\begin{array}{c}\text { EMAS Withdrawals } \\
\text { 2010-First Quarter 2015 }\end{array}$} \\
\hline Large & 258 & $24.36 \%$ & 48 & $12.28 \%$ \\
Medium & 218 & $20.58 \%$ & 52 & $13.30 \%$ \\
Small & 316 & $29.84 \%$ & 219 & $56.01 \%$ \\
Micro & 267 & $25.21 \%$ & 72 & $18.41 \%$ \\
\hline
\end{tabular}

Source: authors' elaboration on ISPRA database.

This observation is even clearer in the period between 2010 and the first quarter of 2015, in which the new registrations of small organizations numbered 127, confronted with 219 withdrawals, with a general decrease of 92 organizations in five years (Table 2). Despite a homogeneous diffusion of EMAS among the four categories, it is noticeable that small organizations represent the group responsible for the larger part of the negative trend in recent years. 
Table 2. New EMAS registrations and withdrawals between 2010 to the first quarter of 2015 per organizations' dimension.

\begin{tabular}{cccc}
\hline Dimension & New Registrations & Withdrawals & Delta \\
\hline Large & 61 & 48 & 13 \\
Medium & 83 & 52 & 31 \\
Small & 127 & 219 & -92 \\
Micro & 134 & 71 & 62 \\
\hline
\end{tabular}

Source: authors' elaboration on ISPRA database.

Table 3 shows that over $64 \%$ of active registrations are located in northern Italy, while the remaining registrations are split between the center and the south. An element that stands out is that the smallest amount of active registrations is in the south. Concurrently, the south also represents $35.55 \%$ of EMAS withdrawals during this period.

Table 3. EMAS active registrations (first quarter of 2015) and withdrawals (2010 to the first quarter of 2015) per geographic area.

\begin{tabular}{ccccc}
\hline & \multicolumn{2}{c}{$\begin{array}{c}\text { Active Registration } \\
\text { First Quarter 2015 }\end{array}$} & \multicolumn{2}{c}{$\begin{array}{c}\text { EMAS Withdrawals } \\
\text { 2010-First Quarter 2015 }\end{array}$} \\
\hline North & 678 & $64.02 \%$ & 174 & $44.50 \%$ \\
Center & 211 & $19.92 \%$ & 78 & $19.95 \%$ \\
South & 170 & $16.05 \%$ & 139 & $35.55 \%$ \\
\hline
\end{tabular}

Source: authors' elaboration on ISPRA database.

Furthermore, southern Italy accounts for the smallest share of new registrations in the last five years $(13.87 \%)$ with a negative delta of 82 organizations (Table 4$)$. On the contrary, in the north the delta is positive for 109 organizations, while the center has maintained a substantial balance $(-7)$. Therefore, the south of Italy is an area where EMAS encounters major difficulties not only in its dissemination, but also in being considered a tool on which organizations can bet for the long term.

Table 4. New EMAS registrations and withdrawals between 2010 and the first quarter of 2015 per organizations' geographic area.

\begin{tabular}{cccc}
\hline Dimension & New Registrations & Withdrawals & Delta \\
\hline North & 283 & 174 & 109 \\
Center & 71 & 78 & -7 \\
South & 57 & 139 & -82 \\
\hline
\end{tabular}

Source: authors' elaboration on ISPRA database.

An analysis of the sector of organizations that have decided to abandon the EMAS regulation is important to emphasize differences between sectors and their strengths and weaknesses).

After a data analysis, we found that $43.3 \%$ of the organizations mainly belong to five specific sectors defined by NACE (Nomenclature Des Activités Économiques Dans Les Communautés Européennes) codes (Regulation (EC) No 1893/2006):

- $\quad 84-$ Public administration and defense; compulsory social security;

- 10-Manufacture of food products;

- $\quad 35-$ Electricity, gas, steam and air conditioning supply;

- 55-Accommodation;

- $\quad 38$-Waste collection, treatment and disposal activities; materials recovery.

As illustrated in Table 5, the sector with the largest number of organizations deleted was that of public administration, defense and compulsory social security with $15.7 \%$, followed by that of the manufacture of food products $(9.9 \%)$. 
Table 5. NACE code of EMAS withdrawals.

\begin{tabular}{lc}
\hline \multicolumn{2}{c}{ NACE code } \\
\hline 84-Public administration and defense; compulsory social security & $15.7 \%$ \\
10-Manufacture of food products & $9.9 \%$ \\
35-Electricity, gas, steam and air conditioning supply & $7.3 \%$ \\
55-Accommodation & $5.5 \%$ \\
38-Waste collection, treatment and disposal activities; materials recovery & $5 \%$ \\
\hline Source: authors' elaboration on ISPRA database. Nace code based on Regulation EC 2006/1893: \\
"establishing the statistical classification of economic activities NACE Revision 2 and amending \\
Council Regulation (EEC) No 3037/90 as well as certain EC Regulations on specific statistical domains".
\end{tabular}

Following the scheme proposed by Heras-Saizarbitoria et al. (2015), in Italy, less than a half of EMAS-registered organizations belong to high environmental impact industries (425 organizations) [57]. Comparing these figures with Table 5, we can observe that from the sectors in which the abandonment rate has been higher, $7.3 \%$ belong to "Electricity, gas, steam and air conditioning supply" (high environmental impact industries). On the other hand, the majority is part of low environmental impact industries (NACE codes 84, 10, 55, 38).

It is also interesting to conduct a joint analysis of the NACE codes (Reg. (EC) No. 1893/2006) and the size of the organizations that have decided to abandon the registration. Public administrations and all the organizations belonging to NACE code 84, which abandoned EMAS, are almost all microsized. The sector of accommodation and that of the manufacture of food products, instead, have registered a prevalence of small-size companies. The sector of electricity, gas, steam and air conditioning supply is mainly composed of large organizations that decided not to renew or to abandon the registration (Table 6).

Table 6. EMAS withdrawals by NACE code and dimensions.

\begin{tabular}{cccccc}
\hline \multirow{2}{*}{ Dimensions } & \multicolumn{5}{c}{ NACE code } \\
\cline { 2 - 6 } & $\mathbf{8 4}$ & $\mathbf{1 0}$ & $\mathbf{3 5}$ & $\mathbf{5 5}$ & $\mathbf{3 8}$ \\
\hline Large & 0 & 2 & 12 & 0 & 7 \\
Medium & 0 & 7 & 9 & 0 & 6 \\
Small & 1 & 29 & 7 & 21 & 6 \\
Micro & 59 & 0 & 0 & 0 & 0 \\
\hline
\end{tabular}

Source: authors' elaboration on ISPRA database.

\section{Conclusions}

Even if Italy represents the leading country in terms of EMAS registrations, starting from 2012, a negative trend in registrations was observed for the first time. In 2015, the delta between new registrations and the dropout rate is strongly negative. The article has given an overview of the characteristics of organizations that have withdrawn from EMAS since 2010 compared with new and active registrations. From the analysis the profile of the organizations that contributed the most to the EMAS reduction, match up with the small organizations operating in southern Italy. This situation can be partially explained considering the Italian economic framework in recent years, in which the global crisis created a tough condition for firms, especially for those of small dimensions and those located in less developed geographic areas. Nevertheless, this phenomenon of withdrawal cannot be completely explained by the recent economic crisis. In fact, the spread of ISO 14001 certification in Italy has constantly grown, from 14,013 certifications in 2010 to 16,351 by the end of 2014 [58].

Our analysis mainly confirmed findings of the previous studies carried out both on ISO 14001 and EMAS, particularly for small organizations. Small firms are often reported as the category which faces major difficulties implementing EMSs [59], and this is mainly due to the lack of human and financial resources to invest $[17,18,41,60]$. Additionally, they are driven by a short-term orientation that does not allow the exploitation of the advantages of sustainability investments, which generally 
have a long-term payoff [53,59]. Other significant issues identified concern the lack of customers' interest in the EMS and the lack of recognition by public institutions [17,41]. D'Alessandro and Masone (2015) found out that in regions where public institutions made incentives available for EMAS registration, the regulation has had greater success among organizations [61]. These findings are confirmed by Daddi et al. (2014), who found out that the introduction of specific measures in order to facilitate access to ISO 14001 and EMAS moderately increases the number of certified firms [21]. An important aspect to consider is that these measures should be effective in the long run (such as tax incentives) in order to avoid abandonments after obtaining the incentive [53,61]. For small organizations, financial support together with simplification measures have a great impact and foster the maintenance of the registration [41,56,62]. Italy also experimented a cluster-based approach to EMAS, which allowed industrial clusters to obtain recognition with an EMAS certificate. This approach promoted the diffusion of the scheme in single organizations and made local stakeholders more aware of the scheme $[41,63,64]$.

In this work an overview of recent trends on the EMAS registrations has been presented. The main limitation of the analysis is that it covers only the Italian context. Given that the negative trend of EMAS is even sharper in other European countries than in Italy, the investigation should be extended to the other main countries where EMAS is more widespread such as Spain and Germany.

EMAS represents European excellence for organizations that wish to improve environmental performances, and it should symbolize a market signal to express commitment towards transparency and improved sustainability. Thus, it would be of great relevance to further investigate the reasons why EMAS numbers are constantly decreasing over Europe. The analysis may focus on organizations that have not renewed their EMAS registration since the beginning of this negative trend. Furthermore, it could also be important to figure out which measures would be more effective and attractive for organizations in order to encourage them to reconsider joining EMAS in the future.

Acknowledgments: We thank ISPRA for the cooperation and support in data collection.

Author Contributions: The authors equally contributed to the reported research. In particular, Roberto Merli and Michele Preziosi worked at the conception of the article, whilst Mara D'Amico contributed to data collection. All the authors developed the data analysis and the related conclusions. All the authors discussed the structure and reviewed the manuscript at all stages, approving the final version of the manuscript.

Conflicts of Interest: The authors declare no conflict of interest.

\section{References}

1. Freeman, R.E.; Reed, D.L. Stockholders and stakeholders: A new perspective on corporate governance. Calif. Manag. Rev. 1983, 25, 93-94.

2. Freeman, R.E. Strategic Management: A Stakeholder Approach, 1st ed.; Harpercollins College Div: Boston, MA, USA, 1984.

3. Clarkson, M.B.E. A stakeholder framework for analyzing and evaluating corporate social performance. Acad. Manag. Rev. 1995, 20, 92-117.

4. Delmas, M.; Toffel, M.W. Stakeholders and environmental management practicicies: An istitutional framework. Bus. Strategy Environ. 2004, 12, 209-222.

5. Stave, K. Participatory system dynamics modeling for sustainable environmental management: Observations from four cases. Sustainability 2010, 2, 2762-2784.

6. Madsen, H.; Ulhøi, J.P. Integrating environmental and stakeholder management. Bus. Strategy Environ. 2001, 10, 77-88.

7. González-Benito, J.; González-Benito, Ó. The role of stakeholder pressure and managerial values in the implementation of environmental logistics practices. Int. J. Product. Res. 2006, 44, 1353-1373.

8. Turner, K.; Pearce, D.; Bateman, I. Environmental Economic, 1st ed.; The John Hopkins University Press: Baltimore, MD, USA, 1994.

9. Field, B.; Field, M.K. Environmental Economics: An Introduction, 6th ed.; McGraw-Hill Education: New York, NY, USA, 2012. 
10. Angell, L.C.; Klassen, R.D. Integrating environmental issues into the mainstream: An agenda for research in operations management. J. Oper. Manag. 1999, 17, 575-598.

11. Neugebauer, F. EMAS and ISO 14001 in the German industry-Complements or substitutes? J. Clean. Prod. 2012, 37, 249-256.

12. Steurer, R.; Langer, M.E.; Konrad, A.; Martinuzzi, A. Corporations, stakeholders and sustainable development i: A theoretical exploration of business-society relations. J. Bus. Ethics 2005, 61, 263-281.

13. Berry, M.; Rondinelli, D. Proactive corporate management: Environmental new industrial revolution. Acad. Manag. Executive 1998, 12, 38-50.

14. Morrow, D.; Rondinelli, D. Environmental management systems: Motivations and results of ISO 14001 and EMAS certification. Eur. Manag. J. 2002, 20, 159-171.

15. Testa, F.; Rizzi, F.; Daddi, T.; Gusmerotti, N.M.; Frey, M.; Iraldo, F. EMAS and ISO 14001: The differences in effectively improving environmental performance. J. Clean. Prod. 2014, 68, 165-173.

16. Feranecová, A.; Jergová, M.; Sabolová, N. Benefits of EMAS easy implementation in SMEs. In Proceedings of the International Conference on Engineering Science and Production Management (ESPM 2015), Tatranská Štrba, Slovak Republic, 16-17 April 2015; CRC Press: Tatranská Štrba, Slovak Republic, 2015; p. 61.

17. Hillary, R. Valuation of Study Reports on the Barriers, Opportunities and Drivers for Small and Medium Sized Enterprises in the Adoption of EMSs; Department of Trade and Industry: London, UK, 1999.

18. Hillary, R. Environmental management systems and the smaller enterprise. J. Clean. Prod. 2004, 12, 561-569.

19. Heras-Saizarbitoria, I.; Arana, G.; Boiral, O. Outcomes of environmental management systems: The role of motivations and firms' characteristics. Bus. Strategy Environ. 2015, doi:10.1002/bse.1884.

20. Testa, F.; Gusmerottia, N.M.; Corsini, F.; Passetti, E.; Iraldo, F. Factors affecting environmental management by small and micro firms: The importance of entrepreneurs' attitudes and environmental investment. Corp. Soc. Responsib. Environ. Manag. 2015, doi:10.1002/csr.1382.

21. Daddi, T.; Testa, F.; Iraldo, F.; Frey, M. Removing and simplifying administrative costs and burdens for EMAS and ISO 14001 certified organizations: Evidences from Italy. Environ. Eng. Manag. J. 2014, 13, 689-698.

22. International Organization for Standardization (ISO). ISO 14001 Continual Improvement Survey 2013 - Final Report and Analysis; ISO: London, UK, 2014.

23. Heras-Saizarbitoria, I.; Boiral, O. ISO 9001 and ISO 14001: Towards a research agenda on management system standards. Int. J. Manag. Rev. 2013, 15, 47-65.

24. To, W.M.; Lee, P.K.C. Diffusion of ISO 14001 environmental management system: Global, regional and country-level analyses. J. Clean. Prod. 2014, 66, 489-498.

25. Marimon, F.; Llach, J.; Bernardo, M. Comparative analysis of diffusion of the ISO 14001 standard by sector of activity. J. Clean. Prod. 2011, 19, 1734-1744.

26. Altin, S.; Altin, A. A study on the expectancies and benefits of companies from the ISO 14001 certification process. Glob. J. Adv. Pure Appl. Sci. 2014, 3, $23-29$.

27. Comoglio, C.; Botta, S. The use of indicators and the role of environmental management systems for environmental performances improvement: A survey on ISO 14001 certified companies in the automotive sector. J. Clean. Prod. 2012, 20, 92-102.

28. Martin-Pena, M.L.; Diaz-Garrido, E.; Sanchez-Lopez, J.M. Analysis of benefits and difficulties associated with firms' Environmental Management Systems: The case of the Spanish automotive industry. J. Clean. Prod. 2014, 70, 220-230.

29. King, A.A.; Lenox, M.J.; Terlaak, A. The strategic use of decentralized institutions: Exloring certifications with the ISO 14001 Management Standard. Acad. Manag. J. 2005, 48, 1091-1106.

30. Matouq, M. The ISO 14001 EMS implementation process and its implications: A case study of Central Japan. Environ. Manag. 2000, 25, 177-188.

31. Moors, E.H.; Mulder, K.F.; Vergrag, P.J. Cleaner production: Barriers and strategies in the base metals producing industry. J. Clean. Prod. 2005, 13, 657-668.

32. Schylander, E.; Martinuzzi, A. ISO 14001-Experiences, effects and future challenges: A national study in Austria. Bus. Strategy Environ. 2007, 16, 133-147.

33. He, W.; Liu, C.; Lu, J.; Cao, J. China economic review impacts of ISO 14001 adoption on fi rm performance: Evidence from China. China Econ. Rev. 2015, 32, 43-56.

34. Delmas, M.A. Barriers and incentives to the adoption of ISO 14001 by firms in the United States. Duke Environ. Law Policy Forum 2000, 11, 105-112. 
35. González-Benito, J.; González-Benito, Ó. Operations management practices linked to the adoption of ISO 14001: An empirical analysis of Spanish manufacturers. Int. J. Prod. Econ. 2008, 113, 60-73.

36. Arena, M.; Azzone, G.; Platti, M. ISO14001: Motivations and benefits in the italian metal industry. Int. J. Eng. Bus. Manag. 2012, doi:10.5772/54786.

37. Matouq, M. A case-study of ISO 14001-based environmental management system implementation in the People's Republic of China. Local Environ. 2000, 5, 415-433.

38. Babakri, K.A.; Bennett, R.A.; Franchetti, M. Critical factors for implementing ISO 14001 standard in United States industrial companies. J. Clean. Prod. 2003, 11, 749-752.

39. Liyin, S.; Hong, Y.; Griffith, A. Improving environmental performance by means of empowerment of contractors. Manag. Environ. Qual. Int. J. 2006, 17, 242-257.

40. Turk, A.M. The benefits associated with ISO 14001 certification for construction firms: Turkish case. J. Clean . Prod. 2009, 17, 559-569.

41. Iraldo, F.; Testa, F.; Frey, M.; Anna, S. Environmental Management System and SMEs: EU Experience, Barriers and Perspectives; Sarkar, S., Ed.; Inthech: Rijeka, Croatia, 2010.

42. Chan, K.-Y.; Li, X.-D. A study of the implementation of ISO 14001 environmental management systems in Hong Kong. J. Environ. Plan. Manag. 2001, 44, 589-601.

43. Darnall, N.; Henriques, I.; Sadorsky, P. Do environmental management systems improve business performance in an international setting? J. Int. Manag. 2008, 14, 364-376.

44. Campos, L.M.S. Environmental management systems (EMS) for small companies: A study in Southern Brazil. J. Clean. Prod. 2012, 32, 141-148.

45. Jenkins, H. Small business champions for corporate social responsibility. J. Bus. Ethics 2006, 67, $241-256$.

46. Ann, G.E.; Zailani, S.; Wahid, N. A study on the impact of environmental management system (EMS) certification towards firms' performance in Malaysia. Manag. Environ. Qual. 2006, 17, 73-93.

47. Massoud, M.A.; Fayad, R.; El-Fadel, M.; Kamleh, R. Drivers, barriers and incentives to implementing environmental management systems in the food industry: A case of Lebanon. J. Clean. Prod. 2010, 18, 200-209.

48. González, C.E. Motivations and Barriers of Implementing an EMS in Spanish Organizations. Master's Thesis, University of East Anglia, Norwich, UK, 2004.

49. Santos, G.; Mendes, F.; Barbosa, J. Certification and integration of management systems: The experience of Portuguese small and medium enterprises. J. Clean. Prod. 2011, 19, 1965-1974.

50. Salomone, R. Integrated management systems: Experiences in Italian organizations. J. Clean. Prod. 2008, 16, 1786-1806.

51. Simon, A.; Karapetrovic, S.; Casadesús, M. Difficulties and benefits of integrated management systems. Ind. Manag. Data Syst. 2012, 112, 828-846.

52. Gianni, M.; Gotzamani, K. Management systems integration: Lessons from an abandonment case. J. Clean. Prod. 2015, 86, 265-276.

53. Heras-Saizarbitoria, I.; Boiral, O.; Arana, G. Renewing environmental certification in times of crisis. J. Clean . Prod. 2016, 115, 214-223.

54. Iraldo, F.; Kahlenborn, W.; Rubik, F.; Hertin, J.; Nielsen, B. EVER: Evaluation of EMAS and Eco-label for Their Revision; European Commission: Brussels, Belgium, 2005.

55. Von Ahsen, A.; Lange, C.; Pianowski, M. Corporate environmental reporting: Survey and empirical evidence. Int. J. Environ. Sustain. Dev. 2004, 3, 5-17.

56. Vernon, J.; Peacoc, M.; Belin, A.; Ganzleben, C.; Candell, M. Study on the Costs and Benefits of EMAS to Registered Organisations; Milieu Ltd.: Brussels, Belgium; Risk and Policy Analysis Ltd.: London, UK, 2009.

57. Heras-Saizarbitoria, I.; Arana, G.; Boiral, O. Exploring the dissemination of environmental certifications in high and low polluting industries. J. Clean. Prod. 2015, 89, 50-58.

58. L'Istituto Superiore per la Protezione e la Ricerca Ambientale (ISPRA). Certificazione ambientale. In Annuario dei Dati Ambientali 2014-2015; ISPRA: Rome, Italy, 2015; pp. 1-24.

59. Granly, B.M.; Welo, T. EMS and sustainability: Experiences with ISO 14001 and eco-lighthouse in Norwegian metal processing SMEs. J. Clean. Prod. 2014, 64, 194-204.

60. Hillary, R.; Thorsen, N. Regulatory and self-regulatory measures as routes to promote cleaner production. J. Clean. Prod. 1999, 7, 1-11.

61. D'Alessandro, B.; Masone, M. Benefici ed Incentivi a Livello Locale per l'adesione ad EMAS ed Ecolabel; ISPRA: Rome, Italy, 2014. 
62. Iraldo, F.; Testa, F.; Tessitore, S.; Daddi, T.; Cautillo, A. L'implementazione del Regolamento EMAS in Italia: Livello di Adozione, Benefici, Barriere ed Incentivi; Istituto Management-Scuola Superiore di Studi Universitari Sant'Anna: Pisa, Italy, 2013.

63. Daddi, T.; de Giacomo, M.R.; Testa, F.; Tessitore, S. Cluster approach and eco-innovation in four industrial clusters of Tuscany region (Italy). Environ. Econ. 2012, 3, 26-34.

64. Merli, R.; Preziosi, M.; Massa, I.; D’Amico, M.; Massa, I. EMAS regulation in italian clusters: Investigating the involvement of local stakeholders. Sustainability 2014, 6, 4537-4557.

(C) 2016 by the authors; licensee MDPI, Basel, Switzerland. This article is an open access article distributed under the terms and conditions of the Creative Commons by Attribution (CC-BY) license (http://creativecommons.org/licenses/by/4.0/). 